\title{
Analysis of genotype-environment interaction in fennel using Sudoku design
}

\author{
Ali F. Al-Mehemdi1 ${ }^{*}$, Medhat M. Elsahookie ${ }^{2}$, Mohammed H Al-Issawi ${ }^{3}$ \\ ${ }^{1}$ Center of Desert Studies, University of Anbar, Iraq \\ ${ }^{2}$ Department of Field Crops Sciences, College of Agriculture, University of Baghdad, Iraq \\ ${ }^{3}$ Department of Field Crops Sciences, College of Agriculture, University of Anbar, Iraq
}

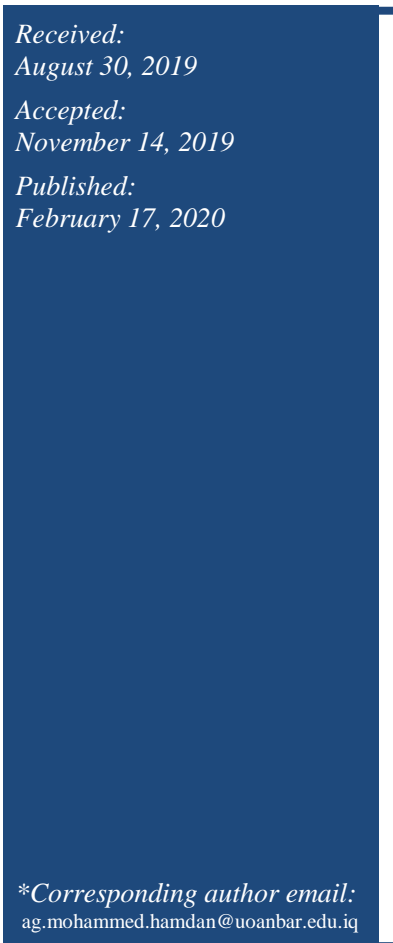

\section{Abstract}

Two trials were carried out over two locations, Ramadi and Fallujah included nine genotypes of Fennel, in order to assess the interaction between genotypes (G) and locations (E) using real data from the two experiments. The nine genotypes of fennel were randomly distributed under with Sudoku square design using type-I and model-I for combined analysis. The methodologies of this type and model solution were explained in details in the current study. Genotypes were significantly differed $(\mathrm{P}<0.01)$ in the first location. In the combined analysis, the genotype by location $(G \times E)$ interaction was also significant $(\mathrm{P}<0.01)$ which is due to the effect of the genotype. It can be concluded that Sudoku square design is suitable for selecting better genotypes as a honeycomb design and to test the multi-environment trial yield. Therefore, augmented studies should be conducted to extract the efficiency of this design using other types and models embedded in this design.

Keywords: GxE interaction, Fennel, Locations, Sudoku design

\section{How to cite this:}

Al-Mehemdi AF, Elsahookie MM and Al-Issawi MH, 2020. Analysis of genotypeenvironment interaction in fennel using Sudoku design. Asian J. Agric. Biol. 8(1):6168. DOI: $10.35495 / a j a b .2019 .07 .314$

This is an Open Access article distributed under the terms of the Creative Commons Attribution 3.0 License. (https://creativecommons.org/licenses/by/3.0), which permits unrestricted use, distribution, and reproduction in any medium, provided the original work is properly cited.

\section{Introduction}

Soil microorganisms services have significant Sudoku is a popular combinatorial puzzle and it is the short form of the Japanese sentence "Suji Wa Dokushin Ni Kagiru" which means that the number should appear only once (Danbaba and Shehu, 2016). Sarkar and Sinha (2015) cited that Wayne Gould from Hong Kong discovered this puzzle while visiting Japan in 1997 and commenced to program computer software for this purpose, then he shared it with TIMES in London (UK) where it was first published in 2004 and ever since it was well known therefore; it consequently, had appeared in newspapers and magazine in Australia, Canada, Eastern Europe, India, and USA. Subramani and Ponnuswamy (2009) proposed the construction of Sudoku designs of order $k=m^{2}$. For applying Sudoku design in agricultural trials, they speculated linear models as a tool to analyze the data resulted from their design. Recently, Sudoku design may have been revealed as partial or NP-complete (nondeterministic polynomial time) (Béjar et al. 2012; Mahdian and Mahmoodian 2015). Likely, Danbaba and Dauran (2016) proposed a linear model and procedure for analyzing data of partially balanced Sudoku designs. In addition, Donovan et al. (2017) and Kumar et al. (2015) investigated the Sudoku extracted space-filling designs. Furthermore, 
Thus, Sudoku design could be used as experimental design as special Latin square design with additional variable (internal block) without maximizing the experimental units (Sarkar and Sinha, 2015) which is represented as orthogonal Graeco-Latin square design to be orthogonal Sudoku square design (Subramani, 2013; Subramani, 2012). Li et al. (2016) proposed a facilitative and effective construction method of uniform designs based on Sudoku applied by a mixed level of factors. Recently, Subramani (2018) explained the rectangles for the construction and analysis of the Sudoku square designs. Experiments could be repeatedly laid out at years, locations (environments) or season with treatments as genotypes then data of interaction of treatments and locations, years or season extracted from these experiments could be analyzed using combined analysis. In response with this particularity, Danbaba and Shehu (2016) and Danbaba (2016) stated combined analysis to analyze data resulted from experiments conducted using Sudoku square design. Consequently, Shehu and Danbaba (2018) applied the analysis of variance method to derive the variance components for the four Sudoku square designs models. For covariance, least square method was applied to derive the sum of the square of the different effects and covariance of Sudoku square design (Shehu and Danbaba, 2018). From the other hand, a multivariate extension of various variables laid out at Sudoku designs could be extracted and done
(Shehu and Danbaba, 2018). As Sudoku can be used in many situations in life, the current study was carried out by using Sudoku design in order to evaluate the performance of nine Fennel genotypes over to environments.

\section{Material and Methods}

Tow field experiments were conducted at two locations viz; Ramadi and Fallujah west of Baghdad, Iraq. Sudoku square design type I was used to randomly distribute nine fennel genotypes (Figure 1).

\begin{tabular}{|c|c|c|c|c|c|c|c|c|c|c|c|c|c|}
\hline \multicolumn{2}{|r|}{2} & 5 & 1 & 9 & & 4 & 2 & 6 & 5 & 71 & 3 & 9 & \\
\hline 8 & & 2 & 3 & 6 & & 8 & 5 & 7 & 2 & 93 & 1 & 4 & 6 \\
\hline & 3 & & & 7 & & 1 & 3 & 9 & 4 & 68 & 3 & 7 & 5 \\
\hline & 1 & & & 6 & & 9 & 7 & 1 & 3 & 85 & 6 & 2 & 4 \\
\hline 5 & 4 & & & 19 & & 5 & 4 & 3 & 7 & 26 & 8 & 1 & 9 \\
\hline & 2 & & & 7 & & 6 & 8 & 2 & 1 & 49 & 7 & 5 & 3 \\
\hline & 9 & & 3 & 8 & & 7 & 9 & 4 & 6 & 32 & 5 & 8 & 1 \\
\hline 2 & & 8 & 4 & 7 & & 2 & 6 & 5 & 8 & 14 & 49 & 3 & 7 \\
\hline & 1 & 9 & & 6 & & 3 & 1 & 8 & 9 & & & 6 & 2 \\
\hline
\end{tabular}

Figure-1: Sudoku puzzle (left) and solved puzzle (right) indicated how the nine (1-9) fennel genotype randomly distributed in the two locations of the study.

Nine genotypes of the fennel were used in the current study (Table 1).

Table-1: Genetic background and some morphological characteristics the fennel genotypes used in the study.

\begin{tabular}{|c|c|c|c|c|}
\hline Symbol & Genotype & Origin & Introduction & Information \\
\hline G1 & Romanesco & Italian & \multirow{2}{*}{$\begin{array}{l}\text { Introduced by the first author } \\
\text { from Poland in } 2010\end{array}$} & \multirow{2}{*}{$\begin{array}{l}\text { Bulbossum, long stem hollow. } \\
\text { The long diameter of the main umbel }\end{array}$} \\
\hline G2 & Amigo & Italian & & \\
\hline G3 & Sahoo & improved & $\begin{array}{l}\text { By Elsahookie from } \\
\text { Azuricum. Name derived } \\
\text { from Elsahookie }\end{array}$ & \multirow[t]{2}{*}{$\begin{array}{l}\text { Bulbossum, semi-long. The low } \\
\text { diameter of main umbel }\end{array}$} \\
\hline G4 & Azuricum & Germany & By Elsahookie in 2013 & \\
\hline G5 & Sajjet & Iranian & From the local market & $\begin{array}{l}\text { long stem hollow Low diameter of the } \\
\text { main umbel }\end{array}$ \\
\hline G6 & Dollap & local & $\begin{array}{l}\text { Cultivated in Dollap town } \\
135 \mathrm{Km} \text { west Baghdad }\end{array}$ & $\begin{array}{l}\text { Short stem. The low diameter of the } \\
\text { main umbel }\end{array}$ \\
\hline G7 & Hannan & Jordan & $\begin{array}{l}\text { By Researcher Hannan from } \\
\text { Dept. of Horticulture named } \\
\text { on his memory }\end{array}$ & $\begin{array}{l}\text { long stem hollow Low diameter of the } \\
\text { main umbel }\end{array}$ \\
\hline G8 & Shuayshae & improved & By irradiation & $\begin{array}{l}\text { Short stem. The low diameter of the } \\
\text { main umbel }\end{array}$ \\
\hline G9 & Di Firenze & Italian & $\begin{array}{l}\text { Introduced by the first author } \\
\text { from Poland in } 2010\end{array}$ & $\begin{array}{l}\text { Bulbossum, long stem hollow. } \\
\text { The long diameter of the main umbel }\end{array}$ \\
\hline
\end{tabular}


Ali F. Al-Mehemdi et al.

Table-2. Data of secondary umbel of nine fennel genotypes grown in Ramadi (L1) and Fallujah (L2) locations.

\begin{tabular}{|c|c|c|c|c|c|c|c|c|c|c|c|c|c|c|c|c|c|c|c|}
\hline \multirow{2}{*}{\multicolumn{2}{|c|}{$\begin{array}{c}\text { Column } \\
\text { box }\end{array}$}} & \multicolumn{9}{|c|}{ (Ramadi-L1) } & \multicolumn{9}{|c|}{ (Fallujah-L2) } \\
\hline & & \multicolumn{3}{|c|}{ CB1 } & \multicolumn{3}{|c|}{ CB2 } & \multicolumn{3}{|c|}{ CB3 } & \multicolumn{3}{|c|}{ CB1 } & \multicolumn{3}{|c|}{ CB2 } & \multicolumn{3}{|c|}{ CB3 } \\
\hline $\begin{array}{l}\text { Row } \\
\text { box }\end{array}$ & $\begin{array}{l}\text { col } \\
\text { row }\end{array}$ & $\mathrm{C} 1$ & $\mathrm{C} 2$ & $\mathrm{C} 3$ & $\mathrm{C} 4$ & $\mathrm{C} 5$ & C6 & C7 & $\mathrm{C} 8$ & C9 & $\mathrm{C} 1$ & $\mathrm{C} 2$ & $\mathrm{C} 3$ & $\mathrm{C} 4$ & $\mathrm{C} 5$ & C6 & C7 & $\mathrm{C} 8$ & C9 \\
\hline \multirow{3}{*}{ RB1 } & $\mathrm{R} 1$ & 43 & 42 & 21 & 17 & 20 & 43 & 34 & 47 & 23 & 22 & 23 & 17 & 39 & 47 & 34 & 45 & 17 & 44 \\
\hline & $\mathrm{R} 2$ & 19 & 16 & 20 & 43 & 47 & 30 & 43 & 39 & 24 & 48 & 40 & 16 & 42 & 43 & 16 & 25 & 35 & 25 \\
\hline & R3 & 41 & 32 & 46 & 35 & 22 & 24 & 42 & 15 & 16 & 35 & 45 & 44 & 24 & 23 & 15 & 16 & 48 & 40 \\
\hline \multirow{3}{*}{ RB2 } & $\mathrm{R} 4$ & 47 & 14 & 45 & 33 & 23 & 18 & 24 & 43 & 36 & 45 & 35 & 25 & 15 & 24 & 47 & 44 & 38 & 17 \\
\hline & R5 & 15 & 31 & 27 & 24 & 44 & 24 & 21 & 43 & 47 & 17 & 48 & 25 & 21 & 43 & 36 & 35 & 45 & 15 \\
\hline & R6 & 21 & 23 & 45 & 44 & 35 & 44 & 15 & 15 & 35 & 15 & 44 & 38 & 35 & 15 & 43 & 25 & 25 & 48 \\
\hline \multirow{3}{*}{ RB3 } & R7 & 12 & 48 & 40 & 22 & 40 & 43 & 16 & 21 & 42 & 26 & 18 & 48 & 42 & 35 & 43 & 40 & 16 & 26 \\
\hline & R8 & 41 & 28 & 16 & 25 & 43 & 38 & 47 & 35 & 16 & 44 & 16 & 34 & 16 & 39 & 21 & 48 & 26 & 43 \\
\hline & R9 & 43 & 42 & 23 & 47 & 20 & 20 & 39 & 22 & 43 & 40 & 26 & 43 & 47 & 16 & 22 & 18 & 44 & 34 \\
\hline
\end{tabular}

Experiments were established during 2016-2017 season using the aforementioned design. Data were collected from plants for many agronomical traits, however, data for number secondary umbels were used as a model to explain this design and the methodology of analysis. Accordingly, data from two locations were recorded based on the solution of the Sudoku puzzle (Table 2).

Thus, data were analyzed as following steps (Locations 1):

1- Calculating the correction factor of the mean

$=\frac{(2552)^{2}}{(3)^{4}}=80403.75$

$$
\text { c. } f .=\Sigma y^{2} \cdots \cdot n_{n^{4}}
$$

2- Calculating the total sum of square (SST)

$$
S S T=\sum_{i=1}^{n^{2}} \sum_{j=1}^{n^{2}} Y^{2} i j-c . f .=\text {; }
$$

$=(43)^{2}+(42)^{2}+\ldots \ldots . .+(34)^{2}-80403.75=$;

$90896-80403.75=10492.25$

3- Calculating the row box sum of squares (SSRB) (Table 3)

$$
S S R B=\sum_{i=1}^{n} \frac{R B^{2} i . .}{n^{3}}-c . f .=
$$

Table-3: Sum of row box data- Location 1

\begin{tabular}{|c|c|}
\hline Row box & ¿RBi.. \\
\hline RB1 & 844 \\
\hline RB2 & 836 \\
\hline RB3 & 872 \\
\hline
\end{tabular}

Thus, the analysis for location one will be

$$
\frac{(844)^{2}+(836)^{2}+(872)^{2}}{3^{3}}-80403.75=26.47
$$

4- Calculating the column box sum of squares (SSCB) (Table 4)

$$
S S C B=\sum_{j=1}^{n} \frac{C B^{2} j . .}{n^{3}}-c . f .=;
$$

Table-4: Sum of row box data- Location 1

\begin{tabular}{|c|c|c|c|}
\hline Column box & CB1 & CB2 & CB3 \\
\hline $\mathbf{\Sigma C B j} .$. & 841 & 868 & 843 \\
\hline
\end{tabular}

Consequently,

$$
\mathrm{SSCB}=\frac{(841)^{2}+(868)^{2}+(843)^{2}}{(3)^{2}}-80403.75=16.77
$$

5- Calculating the row sum of squares (SSR); (Table 5)

$$
S S R=\sum_{l=1}^{n^{2}} \frac{R^{2} l}{n^{2}}-c . f .=
$$

Table-5: Sum of row data - Location 1\&2

\begin{tabular}{|c|c|c|c|}
\hline \multicolumn{2}{|c|}{ Ramadi- L1 } & \multicolumn{2}{c|}{ Fallujah-L2 } \\
\hline Row & $\Sigma \mathrm{R}_{1 . .}$ & Row & $\Sigma \mathrm{R}_{1 . .}$ \\
\hline R1 & 290 & $\mathrm{R} 1$ & 288 \\
\hline R2 & 281 & $\mathrm{R} 2$ & 290 \\
\hline R3 & 273 & R3 & 290 \\
\hline R4 & 283 & R4 & 290 \\
\hline R5 & 276 & R5 & 285 \\
\hline R6 & 277 & R6 & 288 \\
\hline R7 & 284 & R7 & 294 \\
\hline R8 & 289 & R8 & 287 \\
\hline R9 & 299 & R9 & 290 \\
\hline
\end{tabular}


Ali F. Al-Mehemdi et al.

Thus, the analysis will be;

$\mathrm{SSR}=\frac{(290)^{2}+(281)^{2}+\cdots \ldots .+(299)^{2}}{(3)^{2}}-80403.75=58.69$

Thus,

a. extract the column sum of squares 7- Extract the genotypes sum of squares (SSG) (Table 8) (SSC) (Table 6)

$$
S S C=\sum_{p=1}^{n^{2}} \frac{C^{2} p}{n^{2}}-c . f .=
$$

$$
S S G=\sum_{k=1}^{n^{2}} \frac{G^{2} k . .}{n^{2}}-c . f .=
$$

Table-6: Sum of column data - Location 1\&2

\begin{tabular}{|c|c|c|c|c|c|c|c|c|c|}
\hline Location & \multicolumn{10}{|c|}{ Ramadi - L1 } \\
\hline Column & C1 & C2 & C3 & C4 & C5 & C6 & C7 & C8 & C9 \\
\hline $\boldsymbol{\Sigma} \mathbf{C}_{\mathbf{p} . \cdot}$ & 282 & 276 & 283 & 290 & 294 & 284 & 281 & 280 & 282 \\
\hline Location & \multicolumn{10}{|c|}{ Fallujah - L2 } \\
\hline $\boldsymbol{\Sigma}$ Cp.. & 292 & 295 & 290 & 281 & 285 & 277 & 296 & 294 & 292 \\
\hline
\end{tabular}

Consequently,

$\mathrm{SSC}=\frac{(282)^{2}+(276)^{2}+\cdots \ldots+(282)^{2}}{(3)^{2}}-80403.75=25.80$

6- Extract the sum square of sub-square or box of each row box under each column box; (Table 7)

$$
S S S=\sum_{q=1}^{n^{2}} \frac{S^{2} q . .}{n^{2}}-c . f .=
$$

Table-7: Sum of sub-squares data or boxes Location 1

\begin{tabular}{|c|c|c|c|c|c|c|}
\hline Location & \multicolumn{3}{|c|}{ Ramadi -L1 } & \multicolumn{3}{c|}{ Fallujah- L2 } \\
\hline Sub-square & CB1 & CB2 & CB3 & CB1 & CB2 & CB3 \\
\hline RB1 & 280 & 281 & 283 & 290 & 283 & 295 \\
\hline RB2 & 268 & 289 & 279 & 292 & 279 & 292 \\
\hline RB3 & 293 & 298 & 281 & 295 & 281 & 295 \\
\hline
\end{tabular}

Table-8: Sum of nine genotypes data over two locations

\begin{tabular}{|c|c|c|c|}
\hline Genotypes & Ramadi- L1 & Fallujah- L2 & SUM \\
\hline G1 & 386 & 344 & 730 \\
\hline G2 & 386 & 305 & 691 \\
\hline G3 & 309 & 290 & 599 \\
\hline G4 & 336 & 303 & 639 \\
\hline G5 & 149 & 290 & 439 \\
\hline G6 & 208 & 305 & 513 \\
\hline G7 & 156 & 346 & 502 \\
\hline G8 & 202 & 196 & 398 \\
\hline G9 & 420 & 223 & 643 \\
\hline SUM & 2552 & 2602 & 5152 \\
\hline
\end{tabular}

Accordingly,

$\mathrm{SSG}=\frac{(386)^{2}+(386)^{2}+\cdots+(420)^{2}}{(3)^{2}}-80403.75=9971.14$

8- Calculating the error sum of squares (SSE)

$$
S S E=\sum_{i=1}^{n^{2}} \sum_{j=1}^{n^{2}} Y^{2} i j-\sum_{i=1}^{n} \frac{R B^{2} i}{n^{3}}-\sum_{j=1}^{n} \frac{C B^{2} j . .}{n^{3}}-\sum_{i=1}^{n^{2}} \frac{R^{2} l}{n^{2}}-\sum_{p=1}^{n^{2}} \frac{C^{2} p}{n^{2}}-\sum_{k=1}^{n^{2}} \frac{G^{2} k . .}{n^{2}}-\sum_{q=1}^{n^{2}} \frac{S^{2} q . .}{n^{2}}+\frac{5 Y^{2} \ldots .}{n^{4}}=;
$$

So, SSE will be equal to $=90896-80430.22-80430.25-80462.44-80429.56-$ $90374.89-80472.22+402018.80=324.91$

The same aforementioned steps were applied to get the same statistical information for location 2 (Fallujah); therefore ANOVA table constructed for both locations

\begin{tabular}{|c|c|c|c|c|c|c|c|c|c|}
\hline \multirow{2}{*}{ Source Of Variance } & \multirow{2}{*}{ DF } & \multicolumn{2}{|c|}{ DF } & \multicolumn{2}{|c|}{ SS } & \multicolumn{2}{|c|}{ MS } & \multicolumn{2}{|c|}{ F cal. (Observed) } \\
\hline & & L1 & $\mathbf{L 2}$ & L1 & L2 & L1 & $\mathbf{L 2}$ & L1 & $\mathbf{L 2}$ \\
\hline genotypes & $n^{2}-1$ & 8 & 8 & 9971.14 & 2221 & 1246.39 & 277.62 & $168.79 * *$ & 1.43 \\
\hline Row blocks & n-1 & 2 & 2 & 26.47 & 1.21 & 13.24 & 0.61 & 1.79 & 0.003 \\
\hline Column blocks & $n-1$ & 2 & 2 & 16.77 & 33.36 & 8.38 & 16.68 & 1.14 & 0.09 \\
\hline Rows & $n^{2}-1$ & 8 & 8 & 58.69 & 5.65 & 7.34 & 0.71 & 0.99 & 0.004 \\
\hline Columns & $n^{2}-1$ & 8 & 8 & 25.80 & 39.21 & 3.23 & 4.90 & 0.44 & 0.03 \\
\hline Sub-squares (boxes) & $n^{2}-1$ & 8 & 8 & 68.47 & 36.32 & 8.56 & 4.54 & 1.16 & 0.02 \\
\hline Error & $(n-1)\left[(n+1)\left(n^{2}-3\right)-2\right]$ & 44 & 44 & 324.91 & 8546.03 & 7.38 & 194.23 & & \\
\hline Total & $n^{4}-1$ & 80 & 80 & & & & & & \\
\hline
\end{tabular}
as below (Table 9);

Table-9: ANOVA Table of Sudoku design of type-1 of the mean square for both locations (Ramadi-L1 and Fallujah-L2) 
Data presented in ANOVA table indicated that genotypes possessed highly significant effect in location 1which had F calculated of 168.79 and mean squares of 1246.39 secondary umbels per the main umbel. Error mean square was extracted the low value of 7.38. The other components of variance were not significant whereas, at Location of Fallujah (L2) all components of variance were not significant. Thus, error mean square was very high whose value was 194.23 secondary umbels per main umbel (table 9). As least significant difference ( $\left.\mathrm{LSD}_{0.05}\right)$ can be used only if $\mathrm{F}$ test is significant, therefore It was calculated for Location of Ramadi (L1) as it was significant for the treatments (genotypes) as follow:

\section{L.S.D0.05 = todfe $\sqrt{2 m s e / 9}$,}

$=2.035 \sqrt{2 * 7.38 / 9},=2.61$ for genotypes grown over location1, figure 2 showed the significant differences among genotypes at the probability of 0.05 .

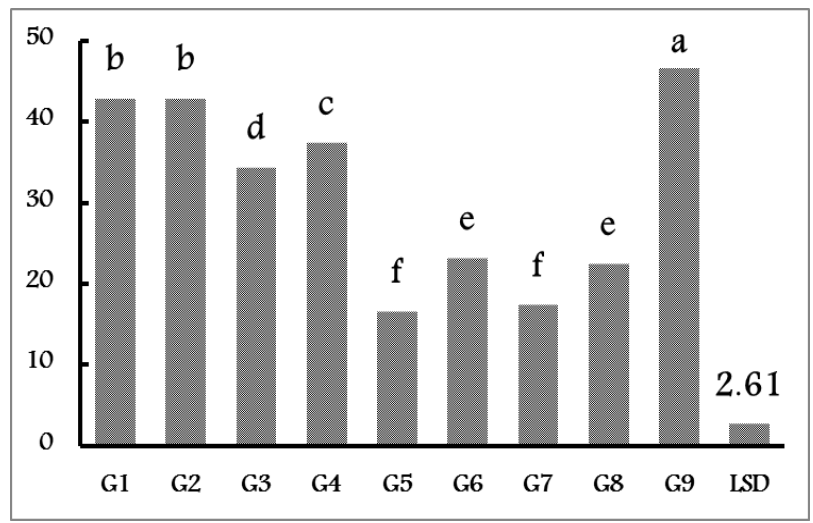

Figure-2. Number of secondary umbel per main umbel for the nine fennel genotypes in Ramadi location (L1) which indicated that G9 was superior overall genotypes under study $(P<0.05)$

\section{Combined analysis of Sudoku}

Data were recorded from two locations for nine genotypes of fennel conducted in Sudoku square design as mentioned above. Thus, the linear model was shifted to be involved in the multi-location experiment as in equation;

$$
\begin{gathered}
y i j \operatorname{lm} x=\mu+\theta x+\alpha i+\beta j x+\delta l x+\gamma m x \\
+(\alpha \theta) i x+\varepsilon(i j) \operatorname{lm} x
\end{gathered}
$$

$$
\left\{\begin{array}{c}
i=1,2, \ldots, k, \text { number of genotypes } \\
j=1,2, \ldots, k, \text { number of sub }- \text { squares } \\
l=1,2, \ldots, k, \text { number of rows } \\
m=1,2, \ldots, k, \text { number of columns } \\
x=1,2, \ldots ., \text { number of locations }
\end{array}\right.
$$

The components of the model interpreted as below; $y_{\mathrm{ijlmx}}$ represents the value which observed in each plot for $l$ th row and $m$ th column, this value is subjected to the $i$ th genotypes, $j$ th sub-square (box) of the $x$ th experimental location; $\mu$ is the general mean, the symbols of $\alpha i, \beta j x, \delta l x, \gamma m x, \theta x$ and $(\alpha \theta) i x$ represent the main effects that influenced by $i$ th genotype, $j$ th sub-square, $m$ th column, $x$ location and genotype by location interaction, respectively. Residual or random error is signed by $\boldsymbol{\varepsilon}_{\mathrm{ijm}}$.

Thus, to complete combined analysis, the sum square of experimental location would be SSEL, SSG is the total genotype sum of squares for both locations, SSR is sum of squares of total rows for both locations, SSC is sum of squares of total columns for both locations, SSS is sum of squares of total sub-squares (boxes or sub-blocks) for both locations, SSI is sum squares of genotypes by locations and SSL is the total sum of squares of both location. To calculate these statistics indices, the following equations were applied;

$$
\begin{aligned}
T 1=\frac{y^{2} \ldots . .}{e k^{2}}, T 2 & =\frac{\sum_{X} y^{2} \ldots . .}{k^{2}}, T 3=\frac{\sum_{l} \sum_{x} y^{2} . . l . x}{k}, T 4 \\
& =\frac{\sum_{m} \sum_{x} y^{2} \ldots m x}{k}, T 5=\frac{\sum_{i} y^{2} i \ldots}{e k}, \\
T 6=\frac{\sum_{x} \sum_{i} y^{2} i \ldots x}{k}, T 7 & =\frac{\sum_{j} \sum_{x} y^{2} . j . x}{k}, T 8=\sum_{i} \sum_{j} \sum_{e} \sum_{m} y^{2} i j l m x
\end{aligned}
$$

(Danbaba, 2016, Danbaba and Shehu, 2016)

Therefore; $\mathrm{T} 1=\frac{5154^{2}}{162}=163973.6$,

From table 8, T2 was calculated:

$\mathrm{T} 2=\frac{(2552)^{2}+(2602)^{2}}{(9)^{2}}=163989 ;$

From table 5 T3 was calculated: $\mathrm{T} 3=$ $\frac{(290)^{2}+(281)^{2}+\cdots+(290)^{2}}{9}=164053.3$

Thus, $\mathrm{SSR}=\mathrm{T} 3-\mathrm{T} 2$;

$=164053.3-163989=64.35$

From table 6 T4 was calculated:T4 = $\frac{(282)^{2}+(276)^{2}+\cdots+(292)^{2}}{9}=164054$

Thus, $\mathrm{SSC}=\mathrm{T} 4-\mathrm{T2}$;

$=164054-163989=65.01$ 
Ali F. Al-Mehemdi et al.

From table8 T5 was calculated:T5 = $\frac{(730)^{2}+(691)^{2}+\cdots+(643)^{2}}{2 x 9}=169847.2$

Thus SSG = T5 $-T 2$;

$=169847.2-163989=5858.24$

From the same table T6 was calculated: T6 = $\frac{(386)^{2}+(344)^{2}+\cdots+(223)^{2}}{9}=176181.1$

From table7, $\mathrm{T} 7$ was calculated: $\mathrm{T} 7=$ $\frac{(280)^{2}+(281)^{2}+\cdots+(295)^{2}}{9}=164093.8$

Thus, SSS=T7 $-T 2$;

$=164093.8-163989=104.79$

$\mathrm{SSL}=T 2-T 1$;

$163989-163973.6=15.4321$

From table2, was calculated: $\mathrm{T} 8=(43) 2+$ $(42) 2+\ldots \ldots . .+(44) 2+(34) 2=185364$

Thus, $\mathrm{SST}=T 8-T 1$;

$185364-163973.6=21390.44$, and SSI $=T 6-T 2-$ $T 5+T 1$

$=176181.1-163989-169847.2+163973.6=6318.45$

Thus, SSE could be found by subtraction as below;

$\mathrm{SSE}=T 8-T 1-T 3-T 4-T 6-T 7+4(T 2)$;

$=185364-163973.2-164053.3-164054-176181.1-$

$164093.8+4(163989)=8964.17$

Table-10: ANOVA table revealed combined analysis of Sudoku square design for nine fennel genotypes

\begin{tabular}{|c|c|c|c|c|}
\hline Source & $\mathbf{d f}$ & $\begin{array}{c}\text { Sum of } \\
\text { squares }\end{array}$ & $\begin{array}{c}\text { Mean } \\
\text { squares }\end{array}$ & $\begin{array}{c}\text { Fcal. } \\
\text { (observed) }\end{array}$ \\
\hline location & $\mathrm{e}-1=2-1=1$ & 15.43 & 15.43 & 0.16 \\
\hline Genotypes & $\mathrm{k}-1=9-1=8$ & 5858.24 & 732.28 & $7.84^{*}$ \\
\hline Rows & $\begin{array}{c}\mathrm{e}(\mathrm{k}-1)=2(9- \\
1)=16\end{array}$ & 64.35 & 4.02 & 0.04 \\
\hline Columns & $\mathrm{e}(\mathrm{k}-1)=2(9-$ & 65.01 & 4.06 & 0.04 \\
\hline $\begin{array}{c}\text { Sub- } \\
\text { squares } \\
\text { (boxes) }\end{array}$ & $\begin{array}{c}\mathrm{e}(\mathrm{k}-1)=2(9- \\
1)=16\end{array}$ & 104.79 & 6.55 & 0.07 \\
\hline $\begin{array}{c}\text { Genotype } \\
\mathrm{X} \text { location }\end{array}$ & $\begin{array}{c}(e-1)(k-1) \\
=(2-1)(9-1) \\
=8\end{array}$ & 6318.46 & 1120.58 & $12.00^{* *}$ \\
\hline Error & $\begin{array}{l}e(k-1)(k-3) \\
=2(9-1)(9-3) \\
=96\end{array}$ & 8964.60 & 93.38 & \\
\hline Total & $\begin{array}{l}e k^{2}-1=2(9)^{2}-1 \\
=161\end{array}$ & 21390.44 & & \\
\hline
\end{tabular}

\section{Results}

\section{Analysis of variance (ANOVA)}

The Analysis of variance (table 9) and Table 10 illustrated that there is a significant difference among fennel genotypes that grown over location1 (Ramadi).
Thus, G9 was superior which showed the highest average of umbellate number per the main umbel of 46.67, followed by G1 and G2 of 42.89 and 42.89 umbellate umbel $^{-1}$ respectively, for each one. Whereas, G5 has the lowest number of umbellate per umbel of 16.56 umbellates umbel $^{-1}$. While the genotypes that sown over location 2 did not show significant differences in the number of secondary umbel per main umbel (Table 11).

Table-11: Means of nine fennel genotypes grown in location $1 \& 2$

\begin{tabular}{|c|c|c|}
\hline Genotypes & Ramadi- L1 & Fallujah- L2 \\
\hline G1 & 42.89 & 38.22 \\
\hline G2 & 42.89 & 33.89 \\
\hline G3 & 34.33 & 32.22 \\
\hline G4 & 37.33 & 33.67 \\
\hline G5 & 16.56 & 32.22 \\
\hline G6 & 23.11 & 33.89 \\
\hline G7 & 17.33 & 38.44 \\
\hline G8 & 22.44 & 21.78 \\
\hline G9 & 46.67 & 24.78 \\
\hline L.S.D $\mathbf{0 . 0 5}$ & $\mathbf{2 . 6 1}$ & N.S. \\
\hline
\end{tabular}

Table-12: Means of umbellate per umbel of nine fennel genotypes over two locations

\begin{tabular}{|c|c|c|c|}
\hline Genotypes & $\begin{array}{c}\text { Ramadi- } \\
\text { L1 }\end{array}$ & $\begin{array}{c}\text { Fallujah- } \\
\text { L2 }\end{array}$ & Means \\
\hline G1 & 42.89 & 38.22 & 40.56 \\
\hline G2 & 42.89 & 33.89 & 38.39 \\
\hline G3 & 34.33 & 32.22 & 33.28 \\
\hline G4 & 37.33 & 33.67 & 35.50 \\
\hline G5 & 16.56 & 32.22 & 24.39 \\
\hline G6 & 23.11 & 33.89 & 28.50 \\
\hline G7 & 17.33 & 38.44 & 27.89 \\
\hline G8 & 22.44 & 21.78 & 22.11 \\
\hline G9 & 46.67 & 24.78 & 35.73 \\
\hline L.S.D 0.05 & \multicolumn{3}{|c|}{8.92} \\
\hline Means & 31.51 & 32.12 & 6.31 \\
\hline L.S.D0.05 & \multicolumn{3}{|c}{} \\
\hline
\end{tabular}

\section{Combined analysis of Sudoku}

Analysis of covariance (Table 10 and 12) indicated that the genotypes of fennel significantly differed. Consequently, G1 showed the highest performance of

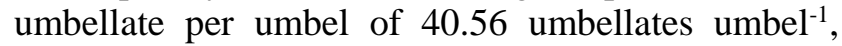
followed by $\mathrm{G} 2$ of 38.39 umbellates umbel $^{-1}$. Whereas, G8 has the lowest performance which gave the lowest number of umbellate of 22.11 umbellates umbel ${ }^{-1}$. Effect of location did not achieve a significant difference. Moreover, the interaction between 
genotype $\mathrm{X}$ location displayed significant differences. Where, G9*L1 gave the highest number of umbellate of 46.67 umbellates umbel ${ }^{-1}$ followed by $\mathrm{G} 1 * \mathrm{~L} 1$ and $\mathrm{G} 2 * \mathrm{~L} 1$ of 42.89 umbellate umbel $^{-1}$ for each one. While G5*L1 had the lowest number of umbellate of 16.56 umbellates umbel ${ }^{-1}$. Furthermore, G7*L2 achieved the highest number of umbellate per umbel of 38.44 umbellates umbel ${ }^{-1}$, followed by $\mathrm{G} 1 * \mathrm{~L} 2$ of 38.22 umbellate umbel $^{-1}$. While G8*L2 gave the lowest number of umbellate per umbel of 21.78 umbellates umbel $^{-1}$.

\section{Discussion}

Not many agricultural researchers have the time or ability to master the details of the complex mathematical operations, yet they all are looking forward to gain a general understanding of the logic of the designs they used. The understanding of the basics and principles of statistics will help to properly design an experiment and get logic conclusions from gained results. The current research was achieved according to real data were recorded on secondary umbel number of nine fennel genotypes that were sown in two locations in the Iraqi environment. Sudoku square design type I was used in order to detect the variation among those genotypes over the two locations. Analysis of variance of nine fennel genotypes over two locations revealed that genotypes in location 1 were significantly varied at the probability of $5 \%$ $(\alpha=0.05)$ when used univariate Sudoku model proposed by Subramani and Ponnuswamy (2009). ANOVA technique was efficiently enhanced by Shehu and Danbaba (2018). The analysis of variance was effective to extract the effect significance variations among genotypes which supported by Subramani (2018) who used Sudoku square designs with rectangles to be applied in many fields of science. The properties of Sudoku designs made those designs were simple and efficient when used in a factorial experiment ( $\mathrm{Li}$ et al., 2016). The combined analysis of genotypes $\mathrm{X}$ location $\left(\mathrm{G}^{*} \mathrm{~L}\right)$ was efficient in revealing the significant differences of some variation components nevertheless location variation effect was not significant. However, genotypes $(\mathrm{G})$ and genotype $X$ location $\left(G^{*} L\right)$ were significant may due to the properties of analysis of covariance. Shehu and Danbaba (2018) discussed the analysis of variance for Sudoku models and significance of treatment who indicated that the use of this combined analysis is a good tool to detect the variation over multi locations especially when they share common treatments.

\section{Conclusion}

Sudoku square design Model Type I assumed as Latin square design in terms of rows, columns, and treatments (genotypes). In the current study, the aforementioned experimental design was used to derivate the variance components over multienvironments. Based on results of the current study, although G9 showed the highest number of secondary umbels per the main umbel in Ramadi (L1) only, G1 showed great stability over the two locations used in this study according to Sudoku Square design type I. yet, support studies should be applied over more divergent environments in order to detect the variation among used treatments.

Disclaimer: None.

Conflict of Interest: None.

Source of Funding: None.

\section{References}

Béjar R, Fernández C, Mateu C and Valls M, 2012. The Sudoku completion problem with rectangular hole pattern is NP complete. Disc. Math. 312(22): 3306-3315.

Danbaba A, 2016. Combined Analysis of Sudoku Square Designs with Same Treatments. Int. J. Math. Comp. Sci. 10(4):189-193.

Danbaba A and Shehu A, 2016. On the Combined Analysis of Sudoku Square Designs with Some Common Treatments. Int. J. Stats. Appls. 6(6): 347-351.

Danbaba A and Dauran NS, 2016. Construction and Analysis of Partially Balanced Sudoku Design of Prime Order. Int. J. Stats. Appls. 6(5): 325-327.

Donovan D, Haaland B and Nott DJ, 2017. A simple approach to constructing quasi-Sudoku-based sliced space-filling designs. Ann. Inst. Stat. Math. 69(4): 865-878.

Kumar A, Varghese C, Varghese E and Jaggi S, 2015. On the construction of designs with three-way blocking. Mod. Assist. Stat. Appli.10(1): 43-52.

Li H, Chatterjee K, Li B and Qin H, 2016. Construction of Sudoku-based uniform designs with mixed levels. Stat. Prob. Lett. 114: 111-118. 
Mahdian M and Mahmoodian ES, 2015. Sudoku Rectangle Completion. Elec. Notes Disc. Math. 49: 747-755.

Sarkar J and Sinha BK, 2015. Sudoku squares as experimental designs. Resonance. 20(9): 788-802.

Shehu A and Danbaba A, 2018. Analysis of covariance of Sudoku square design models. J. Scient. Engin. Res. 5(2): 324-334.

Shehu A and Danbaba A, 2018. Multivariate extension to Sudoku square designs models. J. Sci. Technol. Math. Edu. 14(1): 91-106.

Shehu A and Danbaba A, 2018. Variance components of models of Sudoku square design. Ann. Comp. Sci. Seri. 14(1): 106-113.

Subramani J, 2012. Construction of Graeco Sudoku Square Designs of Odd Orders. Bond. Int. J. Data Mining. 2(2): 37-41.

Subramani J, 2013. Construction and analysis of orthogonal (Graeco) Sudoku square designs. Mod. Mod. Assist. Stat. Appli. 8(3): 239-246.
Subramani J, 2018. Construction and analysis of Sudoku square designs with rectangles. Biom. Biostat. Int. J. 7 (5): 491-497.

Subramani J and Ponnuswamy KN, 2009. Construction and analysis of Sudoku designs. Mod. Assist. Stat. Appli. 4(4):287-301.

\section{Contribution of Authors}

Al-Mehemdi AF: Designed the study and put the hypothesis, performed the measurement and statistical analysis

Elsahookie MM: Designed the study and put the hypothesis

Al-Issawi MH: Performed the measurement and statistical analysis, manuscript writing 